\title{
Mental health status in pregnancy among native and non-native Swedish speaking women: A Bidens study
}

Running headline: Mental health status and ethnicity

Anne-Marie Wangel ${ }^{1}$, Berit Schei ${ }^{2}$, Elsa Lena Ryding ${ }^{3}$, Margareta Östman ${ }^{1}$ and the Bidens study group.

1. Malmö University, Faculty of Health and Society, Malmö, Sweden;

2. Department of Public Health and General Practice /Department of Obstetrics and Gynecology, NTNU/St. Olavs University Hospital, Trondheim, Norway;

3. Department of Obstetrics and Gynecology, Karolinska University Hospital, Karolinska Institutet, Stockholm, Sweden

Corresponding author:

Anne-Marie Wangel

Malmö University, Faculty of Health and Society

Entrance 49, SUS, U304

S-205 06 Malmö, Sweden

E-mail: anne-marie.wangel@mah.se

\section{Conflicts of interest}

The authors state they have no conflicts of interest.

This is an Accepted Article that has been peer-reviewed and approved for publication in the Acta Obstetricia et Gynecologica Scandinavica, but has yet to undergo copy-editing and proof correction. Please cite this article as an "Accepted Article"; doi: 10.1111/j.1600-0412.2012.01512.x 


\begin{abstract}
Objectives. To describe mental health status in native and non-native Swedish-speaking pregnant women and explore risk factors of depression and of posttraumatic stress (PTS) symptoms.
\end{abstract}

Design and setting. A cross-sectional questionnaire study was conducted at midwife-based antenatal clinics in Southern, Sweden.

Sample. A non-selected group of women in mid-pregnancy participated.

Methods. Participants completed a questionnaire including background characteristics, social support, life events, mental health variables and the short Edinburgh Depression Scale.

Main outcome measures. Depressive symptoms during last week and PTS symptoms during past year.

Results. Out of 1003 women, 21.4\% reported another language than Swedish as their mother tongue and were defined as non-native. These women were more likely to be younger, have fewer years of education, potential financial problems, and lack of social support. More nonnative speakers self-reported depressive, PTS, anxiety and, psychosomatic symptoms, and fewer had had consultations with a psychiatrist or psychologist. Of all women $13.8 \%$ had depressive symptoms defined by Edinburgh Depression Scale as 7 or above. Non-native status was associated with statistically increased risks of depressive symptoms and having $\geq 1$ PTS symptom compared to native speaking women. Multivariate modeling including all selected factors resulted in adjusted odds ratios for depressive symptoms of 1.75 (95\% confidence interval: 1.11-2.76) and of 1.56 (95\% confidence interval: 1.10-2.34) for PTS symptoms in non-native Swedish speakers.

Conclusion. Non-native Swedish-speaking women had a more unfavorable mental health status than native speakers. In spite of this, non-native speaking women had sought less mental health care. 
Keywords: depressive, ethnicity, mental health, posttraumatic stress, pregnancy

\author{
Abbreviations: \\ aOR, adjusted odds ratio, \\ EDS, Edinburgh Depression Scale, \\ EPDS, Edinburgh Postnatal Depression Scale, \\ OR, odds ratio,
}

PTS, posttraumatic stress

\title{
Key message
}

Non-native Swedish speaking women seem to be burdened with a poorer mental health status in pregnancy than their national counterparts. Enquiring about a woman's background might illuminate psychosocial factors, facilitating an opportunity to ease her depressive and posttraumatic stress symptoms. 


\section{Introduction}

Migration to an industrialized Western country alters the composition and distribution of risk factors among pregnant women in relation to antenatal care, including psychosocial factors. Health and migration was studied in a large, randomly selected sample of foreign-born and native-born women of childbearing age in 1980 and 1990. A greater risk of poor self-reported health and psychosomatic complaints was found among women born in Southern Europe, refugee women and Finnish women, as compared to Swedish-born women (1). In a USA study where ethnicity was defined by race, an increased adjusted risk of antenatal depression was found in black vs. non-Hispanic white women (2). Other studies of childbearing women have found correlations between ethnicity, psychosocial factors and risk of depression; between proficiency in the native language and access to maternal care; and between duration of residency and adverse birth outcomes (3-6).

Antenatal care provided by midwives is available free of charge to Swedish residents (all of whom have a personal identification number), through the public or private health sectors, and reaches $99 \%$ of all pregnant women. Immigrants are uniformly expected to attend Swedish-for-Immigrants classes as a requirement for access to the social welfare system. In 2008, women of reproductive ages in Malmö, the third largest city in Sweden, were represented by 173 nationalities. More than one-third of them were foreign born, compared to the national average of $20 \%$ (7). Additional differences among childbearing women have been reported in a prospective study from the same catchment area, where an association between lack of social support and having babies who were small-for-gestational age was found in the case of women who have another country of origin than Sweden (8). Country of birth was also included in a national questionnaire-based study of depression during pregnancy (9). One of the findings was that non-native women were more likely to report being depressed than native-born Swedish women. These differences may stem from nonnative women having a disadvantaged social situation, lacking social support, experiencing negative life events and psychological distress, and suffering from mental illness (1-4). The above factors are also likely to be unevenly distributed. Nevertheless, few studies have assessed the broader spectrum of psychological symptoms and mental health status in pregnancy related to ethnicity and potential explanatory factors. 
The aim of this study was to investigate mental health status in pregnancy, including the prevalence of depression and of posttraumatic stress (PTS) symptoms, by comparing native and non-native Swedish-speaking women, and explore factors influencing differences between the two groups.

\section{Material and methods}

A questionnaire-based study of an unselected group of pregnant women at six public and two private antenatal clinics within the catchment area of a University Hospital in Southern Sweden, was done between 1 March and 30 November 2008. Women attending these clinics represent almost $80 \%$ of all delivering women at the hospital. All women in the second to third trimester, who spoke fluent Swedish while in contact with their midwife, were consecutively given a letter with information about the study. Data collection applied to consenting women when they had a routine glucose intolerance test at 28 to 29 gestational weeks. Each woman was asked to complete the questionnaire in Swedish while at the clinic and place it in a sealed envelope together with her signed informed consent. Most women filled out the questionnaire during gestational weeks 27 to 30 (mean 28.6, $\mathrm{SD} \pm 1.73$ ). One question addressed ethnicity by asking, "Is your mother tongue other than Swedish? If so, please state the language." Those reporting a language other than Swedish were categorized as non-native-speakers.

Participation in the study was voluntary. The clinical care a woman received was not affected in any way. A woman having intensified feelings of depression or stressful memories could contact her midwife while completing the questionnaire or at the next visit, in which case she would be further assessed or referred for psychosocial counseling. Records relating to nonparticipants were not allowed in accordance with the Swedish Privacy Protection Law. The Regional Ethics Committee of Stockholm, Sweden, approved the study (Reg. no. 2006/354-31).

Our project was part of the Bidens study, a European investigation of life-time experiences, delivery expectations, and outcomes (10). The eight page Bidens questionnaire included questions validated and applied in a Nordic study among gynecological patients addressing socio-demographic status, abuse history, self-estimated health, anxiety, psychosomatic and PTS symptoms. The item wording was already available in Swedish and the Nordic Abuse Questionnaire (NorAQ) has been validated in Swedish $(11,12)$. Other questions of 
background characteristics, social support, and the use of medicine were adapted from the Norwegian Mother and Child study (13). We also incorporated the Swedish version of the modified questions of life event and additional background items that have been used by others previously $(9,14,15)$.

Social support was measured by means of two questions "Are you living with partner or not?" and "Do you have someone besides your husband or partner to confide in?" The answer alternatives were coded No (for no one) and Yes (for having one or more persons). Questions of negative life events experienced in the last 12 months included nine items: serious illness, accidents, injuries, death, divorce, problems with family and friends at home or work, or financial or employment difficulties affecting oneself or a relative. An affirmative reply was coded as Yes. Missing values $(n=40)$ of the above events were coded as No. We used a cutoff point at two or more events for statistical analysis (9). Potential financial problems were further investigated by asking, "If you received a bill of SEK 20000.00 (approx. USD 2850), how easy would it be for you to pay it within a week?" (15). Those indicating having none or some difficulties were recoded as No before statistical analyses. Others indicating it would be "very difficult" were defined as experiencing financial distress (1).

A history of seeking professional support due to personal problems was investigated. Contacts with a psychiatrist or psychologist prior to pregnancy were categorized as No (if the answer were "no", or "yes, while pregnant") or Yes (if the answer was "yes, previous to pregnancy"). An additional four items investigated medications taken during the past year, such as the use of sleeping pills, tranquilizers, anti-depressants, or other psychotropic drug (missing values, $\mathrm{n}=54, \mathrm{n}=82, \mathrm{n}=85$ and $\mathrm{n}=84$, respectively). Answers were categorized into No ("Not at all" or "rarely") or Yes ("for a short time", "for a long period", or "regularly").

The Edinburg Postnatal Depression Scale (EPDS) has been validated in Swedish and for the detection of depressive symptoms during pregnancy, with an optimal cut-off at $\geq 13(16,17)$. We used the Swedish questions corresponding to the short version of the EPDS, EDS-5. It includes five items rated on a 0 to 3 scale, yielding a range of 0 to 15 , with higher scores indicating more depressive symptoms for the week prior to the study. Compared to the full version containing 10 items, the correlation has been estimated at 0.96 (18). A cut-off at $\geq 7$ 
was defined for having moderate and $\geq 8$ for severe symptoms of depression. We chose $\geq 7$ for the purpose of logistic regression. The EDS-5 score was computed only for those responding to all five items (missing $=22$ ).

PTS symptoms in the last 12 months were addressed by three questions from the NorAQ: intrusive memories, avoidance of certain situations, and emotional numbness (19). Those answering "sometimes" or "often" to at least one of the three symptoms were defined as having suffered from PTS. Women indicating to have these symptoms "rarely" or not at all, or had missing values for the three items $(n=6+6+7)$ were coded No before logistic regression of the PTS variable. Self-estimated symptoms of anxiety and of psychosomatic symptoms were assessed by the question: "During the last 12 months, have you suffered from anxiety to such an extent that you have found it hard to cope with your daily life?", and "During the last 12 months, have you suffered from physical ailments (e.g. stomach-ache, headache, dizziness or muscular pain) to such an extent that you have had problems in with your daily life?" Women reporting having anxiety and psychosomatic symptoms "often" or "sometimes" were classified as Yes, or No, if the answer was not at all, "rarely", or was missing (19).

\section{Statistical analysis}

We analyzed nominal and categorical variables using Pearson's chi-squared and Fisher's exact test for differences between native and non-native speakers of Swedish. Student's $t$-test was used for continuous variables. Missing values of background and independent variables were equally distributed in the two groups, and not included in the regression analyses. Crude odds ratios (OR) between selected psychosocial characteristics and the dependent variables were estimated based on language status. We analyzed the adjusted risk estimates (aOR) of depression and PTS in non-native Swedish speaking women vs. native women as reference, using four models based on a priori selected covariates. Model 1 comprised the background variables of increasing age of the participants (in years, continuous variable), having had $\leq 13$ years of education, and experiencing financial distress. Model 2 comprised age and social support (not living with a partner, and having no one to confide in). Model 3 comprised age and professional support (consultation with a psychiatrist or psychologist previous to pregnancy). All of the above factors were included in model 4. 
All analyses were two-sided $(p<0.05)$. We report $95 \%$ confidence intervals of the risk estimates. SPSS 18.0 statistical software package (SPSS, Chicago, IL, USA) was used for the analyses.

\section{Results}

In total 1025 women filled out the questionnaire, but 22 did not indicate mother tongue status and were excluded from analysis. Of the remaining 1003 women $21.4 \%$ indicated their ethnic language to be other than Swedish as follows: other Nordic (2.8\%); West Germanic/Northern European (4.8\%); Slavic and Central European (6.0\%); Arabic, Turkish, and Kurdish (4.5\%); Asian or unspecified languages (3.4\%).

Background characteristics are shown in Table 1. The mean age of the all participating women was 30.3 ( $\mathrm{SD} \pm 4.68$ ), but was lower in non-native women $29.0(\mathrm{SD} \pm 5.11, p<$ 0.001). Compared to native women, non-native Swedish-speaking women had fewer years of education and greater potential financial problems. Also unevenly distributed between the two groups were, lack of social support, not living with a partner, and having no one in whom to confide. The total number of items categorized as negative life events did not differ, although reporting specific life events varied between the groups. Thus, native speaking women were more likely to report having problems with family or having lost someone close to them $(p=0.009)$. By contrast, non-native Swedish speakers were more likely to report having financial problems in the last 12 months $(p<0.000)$ (data not shown).

Table 2 shows the proportion and measures of psychological symptoms, professional support, and reported use of medication during the last 12 months. A total of $13.8 \%$ of all women had moderate symptoms of depression, a condition that was more common in non-native women ( $p<0.001)$. Among women, with other Nordic and West Germanic languages, who scored EDS $\geq 7$ were $6.2 \%$, respectively, $7.9 \%$, higher than in native Swedish speakers, and thus kept as non-ethnic Swedes (data not shown). PTS symptoms were reported by $12 \%$ to $30 \%$ of the women. More non-native women reported having at least one of three PTS symptoms, compared to native Swedish speaking women $(p<0.001)$. More non-native than native Swedish speakers had used tranquilizers $(p=0.014)$. Antidepressants were taken by about $6 \%$ of both groups. Few women had used any other psychotropic medication. 
Women, who were younger, were experiencing financial distress, were not living with a partner, had no one to confide in, and had previously consulted a mental health care professional showed significantly increased crude ORs for depressive and PTS symptoms in the case of both native and non-native women. Lacking higher education was only associated with depressive symptoms. Table 3 shows adjusted risk estimates of depression and PTS symptoms. The elevated aORs of mental health status in non-native women were only partly explained by background or social support factors, but not by previously having seen a psychiatrist or psychologist.

\section{Discussion}

In studying depressive and PTS symptoms among pregnant women in a multicultural city population in Sweden we identified a high overall prevalence of poor mental health. Selfestimated symptoms of depression and PTS, anxiety, and psychosomatic symptoms were significantly more common among non-native than in native Swedish-speaking women. Furthermore, non-native women were less likely to have seen a psychiatrist or psychologist prior to pregnancy. Their reported use of anti-depressant medication was the same as in native Swedish speaking women.

Among the limitations of this study was its cross-sectional design, which did not allow any casual explanation of the associations. All women communicating with their midwife in fluent Swedish were invited. Some declined participation after seeing the questionnaire. Missing data were evenly distributed between the two ethnic groups. Questions about mental health that inquired into the last 12 months may have resulted in some misclassification due to memory bias. The questions about mental health status (except the EDS-5 instrument) were taken from the NorAQ (12). This particular part of the Bidens study questionnaire would have benefitted from incorporating other validated instruments of anxiety, psychosomatic symptoms and PTS (20). Since this this was not done, the results must be interpreted with caution. One previous study did use the same three PTS questions about symptoms of intrusion, avoidance, and numbing in investigating associations with adverse experiences in health care (11). As the co-morbidity of perinatal depression and PTS is well known (21), PTS symptoms (such as emotional numbness), as measured in this study might partly overlap with symptoms of depression. 
We used the short version EDS-5 and found a significantly higher prevalence of depressive symptoms with $\geq 8$ as a cut-off in non-native as compared with native Swedish-speaking women (18.4\% and 6.7\%, respectively). Similar differences between non-native and women with native Swedish language were found during early pregnancy in a national sample done in 1999 and 2000, using the EPDS at $\geq 14$ (15.3\% and 6.9\%, respectively) (9).

We used mother tongue as a proxy for ethnicity, as others have also done. In a Canadian community study it was found an increased (non-significant) risk for major depression in women speaking languages other than French or English (adjusted for age, sex, income, marital, and immigrant status, as well as chronic condition and psychological stress) (22). However, a question of country of birth might have been a better choice. This was recently recommended by an expert panel as a core perinatal health indicator, followed by length of time in a country and language fluency (23).

Few studies have actually compared mental health during pregnancy in native-born and nonnative born women $(1,3)$. One example is the Mothers in a New Country Study (4), which concluded that age, homesickness, loneliness, and inadequate English were contributing factors to maternal depression. Also in our study, socioeconomic factors (model 1), and social support (model 2), exerted some influence. Financial distress (1) was the strongest independent factor associated with depressive and PTS symptoms (OR 2.31; 95\% CI 1.563.42 and $2.75 ; 1.77-4.27$, respectively). We chose to include "consultations with a psychiatrist or psychologist previous to pregnancy" since this could be an indication of a preexisting mental illness that might influence mental health in pregnancy. However, adding this factor (model 3) did not influence the risk of depressive or PTS symptoms. This was probably because non-native speakers, in spite of a greater risk of mental health problems, had consulted such professionals less than native Swedish speakers. A higher threshold for seeking psychiatric health care has also been found in immigrants in an interview study of a similar population (24).

After controlling for the factors of model 1-3, non-native women had a greater risk of selfestimated symptoms of depression and PTS. Other social factors not investigated, such as housing or employment status of the woman or her partner, or awaiting one's partner's immigration, might explain more of the differences found. Experiences of past or present 
domestic violence and abuse might also influence a woman's mental health in different ways (25). A large proportion of the non-native population of Malmö are refugees, who have sought asylum from global war zones over the past twenty years, or are the second generation of these migrants. The life-event questions used did not solicit information on events that took place more than 12 months ago. Non-native Swedish speaking women or members of their immediate family might have been subjected to more traumatic events in their earlier lives.

Recruitment was consecutive, but due to ethical considerations we were not allowed to record any information about women who declined to participate. We estimated the response rate at $78 \%$ of the total number of pregnant women attending public antenatal clinics during the recruitment period (clinics in the private sector not included). More non-native Swedish than native speakers might have been among the non-responders. If their symptom load were also higher than what was estimated for native Swedish speakers, an overly conservative estimate of the associations between non-natives and symptoms of depression and PTS might be the result. No data on the proportion of childbearing women mastering the Swedish language were available. Our findings can only be generalized to non-native women with sufficient knowledge of Swedish.

\section{Conclusions}

Pregnant women whose mother tongue was not Swedish seemed burdened by more social problems and poorer mental health than their native-born Swedish speaking counterparts, even if they spoke Swedish fluently. They had a greater risk of symptoms of depression and PTS, but had availed themselves of psychiatric or psychological services less often than native Swedish women, and they had not used antidepressants more frequently. Antenatal care providers need to pay attention to this group of women by systematically assessing their ethnic background and offering them more preventive care, appropriate support, and treatment.

\section{Funding}

Funding was provided by a grant from the Faculty of Health and Society, Malmö University, Sweden. The Bidens study was supported by the Daphne II Program to combat violence against children, young people, and women: European Commission for Freedom, Security, 
and Justice, Brussels, Belgium (Grant no. JLS / 2006/DAP-1/242/W30-CE-0120887 /0087).

\section{Acknowledgements}

We thank the Department of Obstetrics and Gynecology at the Scania University Hospital, Malmö, and the midwives at the participating antenatal clinics for their support.

The Bidens study group: Berit Schei (principal investigator), Department of Public Health and General Practice/ Department of Obstetrics and Gynecology, NTNU/St. Olavs University Hospital, Trondheim, Norway; Elsa Lena Ryding (co-principal investigator), Karolinska Institutet/ Karolinska University Hospital, Stockholm, Sweden; Mirjam Lukasse (coordinator), NTNU, Norway. Local principal investigators: Marleen Temmerman (University of Ghent, Belgium); Thora Steingrímsdóttir (Landspitali University Hospital, Iceland); Ann Tabor (Rigshospitalet, Denmark); Helle Karro (University of Tartu, Estonia). Local coordinators: An-Sofi Van Parys (University of Ghent, Belgium); Hildur Kristjánsdóttir (Landspitali University Hospital, Iceland); Anne-Mette Schroll (Rigshospitalet, Denmark); Made Laanpere (University of Tartu, Estonia); Anne-Marie Wangel (Malmö University, Sweden).

\section{References}

1. Iglesias E, Robertson E, Johansson SE, Engfeldt P, Sundquist J. Women, international migration and self-reported health. A population-based study of women of reproductive age. Soc Sci Med. 2003; 56: 111-24.

2. Gavin AR, Melville JL, Rue T, Guo Y, Dina KT, Katon WJ. Racial differences in the prevalence of antenatal depression. Gen Hosp Psychiatry. 2011; 33: 87-93.

3. Edwards B, Galletly C, Semmler-Booth T, Dekker G. Antenatal psychosocial risk factors and depression among women living in socioeconomically disadvantaged suburbs in Adelaide, South Australia. Austr NZ J Psychiatry. 2008; 42: 45-50.

4. Small R, Lumley J, Yelland J. Cross-cultural experiences of maternal depression: Associations and contributing factors for Vietnamese, Turkish and Filipino immigrant women in Victoria, Australia. Ethn Health. 2003; 8: 189-206.

5. Shi L, Lebrun LA, Tsai J. The influence of English proficiency on access to care. Ethn Health. 2009; 14: 625-42. 
6. Urquia M, Frank J, Moineddin R, Glazier R. Immigrants' duration of residence and adverse birth outcomes: A population-based study. BJOG. 2010; 117: 591-601.

7. Socialstyrelsen. Graviditeter, förlossningar och nyfödda barn, medicinska födelseregistret 1973-2007 (Pregnancy, deliveries and newborn infants, the Swedish medical birth register). Stockholm: Socialstyrelsen; 2009-125-5.

8. Dejin-Karlsson E, Östergren PO. Country of origin, social support and the risk of small for gestational age birth. Scand J Public Health. 2004; 32: 442-9.

9. Rubertsson C, Waldenström U, Wickberg B. Depressive mood in early pregnancy: Prevalence and women at risk in a national Swedish sample. J Reprod Infant Psychol. 2003; 21: 113-23.

10. Lukasse M, Vangen S, Øian P, Kumle M, Ryding EL, Schei B. Childhood abuse and fear of Childbirth-A Population-based study. Birth. 2010; 37: 267-74.

11. Wijma B, Schei B, Swahnberg K, Hilden M, Offerdal K, Pikarinen U, et al. Emotional, physical, and sexual abuse in patients visiting gynaecology clinics: A nordic cross-sectional study. Lancet. 2003; 361: 2107-13.

12. Swahnberg IM, Wijma B. The NorVold abuse questionnaire (NorAQ): Validation of new measures of emotional, physical, and sexual abuse, and abuse in the health care system among women. Eur J Public Health. 2003; 13: 361-6.

13. Rosand G, Slinning K, Eberhard-Gran M, Roysamb E, Tambs K. Partner relationship satisfaction and maternal emotional distress in early pregnancy. BMC Public Health. 2011; 11: 161 .

14. Rosengren A, Orth-Gomér K, Wedel H, Wilhelmsen L. Stressful life events, social support, and mortality in men born in 1933. Br Med J. 1993; 307: 1102.

15. Statistiska centralbyrån. ULF - undersökning av levnadsförhållanden ULF-Survey on Swedish living conditions). Stockholm, Sweden: Official Statistics of Sweden; 2007.

16. Wickberg B, Hwang CP. The Edinburgh Postnatal Depression Scale: Validation on a Swedish community sample. Acta Psychiatr Scand. 1996; 94: 181-4.

17. Rubertsson C, Börjesson K, Berglund A, Josefsson A, Sydsjö G. The Swedish validation of Edinburgh Postnatal Depression Scale (EPDS) during pregnancy. Nordic J Psychiatry. 2011: 1-5.

18. Eberhard-Gran M, Eskild A, Samuelsen S, Tambs K. A short matrix-version of the Edinburgh Depression Scale. Acta Psychiatr Scand. 2007; 116: 195-200.

19. Swahnberg K, Schei B, Hilden M, Halmesmäki E, Sidenius K, Steingrimsdottir T, et al. Patients' experiences of abuse in health care: A Nordic study on prevalence and associated factors in gynecological patients. Acta Obstet Gynecol Scand. 2007; 86: 349-56. 
20. Ayers S. Assessing psychopathology in pregnancy and postpartum. J Psychosom Obstet Gynaecol. 2001; 22: 91-102.

21. Söderquist J, Wijma K, Wijma B. Traumatic stress in late pregnancy. J Anxiety Disord. 2004; 18: 127-42.

22. Vasiliadis H, Lepnurm M, Tempier R, Kovess-Masfety V. Comparing the rates of mental disorders among different linguistic groups in a representative Canadian population. Soc Psychiatry Psychiatr Epidemiol. 2012; 47: 195-202.

23. Gagnon AJ, Zimbeck M, Zeitlin J. Migration and perinatal health surveillance: An international Delphi survey. Eur J Obstet Gynecol Reprod Biol. 2010; 149: 37-43.

24. Ingvarsdotter K, Johnsdotter S, Östman M. Normal life crises and insanity: Mental illness contextualized. European J Social Work. In press. DOI:10.1080/13691457.2010.545771

25. Ellsberg M, Jansen HA, Heise L, Watts CH, Garcia-Moreno C. Intimate partner violence and women's physical and mental health in the WHO multi-country study on women's health and domestic violence: An observational study. Lancet; 371: 1165-72. 
Table 1. Background charac teristic s of native and non-native Swedishspeaking women

\begin{tabular}{|c|c|c|c|c|}
\hline & $\begin{array}{c}\text { All } \\
\text { women } \\
\mathrm{N}=1003 \\
\mathrm{n}(\%)\end{array}$ & $\begin{array}{c}\text { Native } \\
n= \\
788 \\
(\%)\end{array}$ & $\begin{array}{l}\text { Non- } \\
\text { native } \\
n=215 \\
(\%)\end{array}$ & $\begin{array}{r}p- \\
\text { value }^{a}\end{array}$ \\
\hline \multicolumn{5}{|l|}{ Age in years } \\
\hline$<25$ & $112(11.2)$ & 8.4 & 21.4 & 0.001 \\
\hline $25-29$ & 321 (32.0) & 31.5 & 34.0 & \\
\hline $30-35$ & 443 (43.2) & 46.1 & 32.6 & \\
\hline$>35$ & $137(13.7)$ & 14.1 & 12.1 & \\
\hline \multicolumn{5}{|l|}{ Education $(\mathrm{n}=990)$} \\
\hline$\leq 13$ years & 339 (34.2) & 30.8 & 47.1 & $<0.000$ \\
\hline$\geq 14$ years & $651(65.8)$ & 69.2 & 52.9 & \\
\hline \multicolumn{5}{|l|}{$\begin{array}{l}\text { Fina ncial distress }(\mathrm{n}= \\
977)\end{array}$} \\
\hline No & 701 (69.9) & 77.5 & 50.5 & \\
\hline Yes, some & 186 (18.5) & 16.4 & 28.8 & \\
\hline Yes & $90(9.0)$ & 6.1 & 20.7 & 0.002 \\
\hline \multicolumn{5}{|l|}{ Social support $(n=1000)$} \\
\hline Living w/partner & $963(96.0)$ & 97.1 & 92.1 & \\
\hline Not living w/ partner & $40(4.0)$ & 2.9 & 7.9 & 0.002 \\
\hline No one to confide in & $37(3.7)$ & 1.8 & 10.8 & 0.004 \\
\hline Confide in $1-2$ persons & 330 (32.9) & 30.4 & 42.7 & \\
\hline Confide in several & $633(63.3)$ & 67.9 & 46.5 & \\
\hline \multicolumn{5}{|l|}{$\begin{array}{l}\text { Negative life events } \\
(n=963)\end{array}$} \\
\hline No events & $472(47.1)$ & 47.7 & 54.3 & \\
\hline Life event 1 & $232(23.1)$ & 25.2 & 19.8 & \\
\hline Life events $\geq 2$ & 259 (25.8) & 27.2 & 25.9 & \\
\hline
\end{tabular}

a Comparing native and non-native Swedish-speaking women by Pearson chi-square or Fisher's exact test, level of signific ance $p<0.05$. 
Table 2. Self-reported symptoms of mental health sta tus and treatment indic ators a mong native and non-native Swedish-speaking women

\begin{tabular}{|c|c|c|c|c|}
\hline & $\begin{array}{c}\text { All women } \\
\mathrm{N}=1003 \\
\mathrm{n}(\%)\end{array}$ & $\begin{array}{r}\text { Native } \\
\mathrm{n}=788 \\
(\%)\end{array}$ & $\begin{array}{r}\text { Non- } \\
\text { native } \\
\mathrm{n}=215 \\
(\%)\end{array}$ & $\begin{array}{r}p- \\
\text { value } \\
\text { a }\end{array}$ \\
\hline $\begin{array}{l}\text { EDS-5 past week } n=981 \\
\geq 7 \text { points }\end{array}$ & $138(13.8)$ & 11.5 & 21.9 & \\
\hline$\geq 8$ points & $89(9.1)$ & 6.7 & 18.4 & $\begin{array}{r}<.001 \\
0.001\end{array}$ \\
\hline \multicolumn{5}{|l|}{$\begin{array}{l}\text { Symptoms in the past } 12 \\
\text { months }\end{array}$} \\
\hline No, PTS & $697(69.5)$ & 72.3 & 59.1 & \\
\hline Yes, PTS & $306(30.5)$ & 27.7 & 40.9 & 0.001 \\
\hline Yes, anxiety & $185(18.2)$ & 15.6 & 28.8 & $0.001<$ \\
\hline Yes, psychosomatic & $203(20.3)$ & 15.6 & 37.2 & 0.001 \\
\hline \multicolumn{5}{|l|}{$\begin{array}{l}\text { Medication during to past } \\
\text { year: short/long periods or } \\
\text { regularly }\end{array}$} \\
\hline Yes, a nti-depressants & $54(5.8)$ & 5.8 & 6.0 & \\
\hline Yes, tranquilizers & $38(4.1)$ & 3.2 & 7.5 & 0.014 \\
\hline Yes, sleep medication & $32(3.5)$ & 3.2 & 4.5 & \\
\hline Yes, other psyc hotropic & 14 (1.5) & 1.4 & 2.0 & \\
\hline $\begin{array}{l}\text { drugs } \\
\text { Seen }\end{array}$ & & & & \\
\hline \multicolumn{5}{|l|}{$\begin{array}{l}\text { seen } \\
\text { psychia trist/psyc holog ist }\end{array}$} \\
\hline Never & $677(67.5)$ & 65.0 & 76.7 & \\
\hline Yes, during pregnancy & $57 \quad(5.7)$ & 5.7 & 5.6 & \\
\hline Yes, previous to pregnancy & $265(26.4)$ & 28.9 & 17.2 & 0.004 \\
\hline
\end{tabular}

a Comparing native and non-native Swedish-spea king women by Pearson's or Fisher's exact test, level of signific ance $p<0.05$.

EDS, Edinburgh Depression Scale-5; PTS, posttraumatic stress 
Table 3. Associations of depressive a and posttrauma tic stress ${ }^{b}$ symptoms in pregnancy with being native or non-native Swedish spea kers $(\mathrm{N}=1003)$

\begin{tabular}{|c|c|c|c|c|c|c|c|c|c|c|c|c|}
\hline & $\begin{array}{r}\text { Cases } \\
n\end{array}$ & $\begin{array}{r}\text { Cases } \\
(\%)\end{array}$ & $\begin{array}{l}\text { Crude } \\
\text { OR }\end{array}$ & $\begin{array}{l}95 \% \\
\mathrm{Cl}\end{array}$ & $\begin{array}{l}\text { Model } \\
1^{c} \\
\text { aOR }\end{array}$ & $\begin{array}{l}95 \% \\
\mathrm{Cl}\end{array}$ & $\begin{array}{l}\text { Model } \\
2^{\mathrm{d}} \\
\mathrm{aOR}\end{array}$ & $\begin{array}{l}95 \% \\
\mathrm{Cl}\end{array}$ & $\begin{array}{l}\text { Model } \\
3^{e} \\
\text { aOR }\end{array}$ & $\begin{array}{l}95 \% \\
\mathrm{Cl}\end{array}$ & $\begin{array}{l}\text { Model } \\
4^{f} \\
\text { aOR }\end{array}$ & $\begin{array}{l}95 \% \\
\mathrm{Cl}\end{array}$ \\
\hline $\begin{array}{l}\text { Depression } \\
\text { last } 7 \text { days }\end{array}$ & 138 & (13.8) & & & & & & & & & & \\
\hline $\begin{array}{l}\text { Native } \\
\text { Swedish } \\
\text { speakers }\end{array}$ & 98 & (11.5) & 1 & & 1 & & 1 & & 1 & & 1 & \\
\hline $\begin{array}{l}\text { Non- } \\
\text { native } \\
\text { Swedish } \\
\text { speakers }\end{array}$ & 47 & (21.9) & 2.31 & $\begin{array}{l}1.56- \\
3.42\end{array}$ & 1.70 & $\begin{array}{l}1.11- \\
2.61\end{array}$ & 1.81 & $\begin{array}{l}1.19- \\
2.74\end{array}$ & 2.34 & $\begin{array}{l}1.55- \\
3.54\end{array}$ & 1.75 & $\begin{array}{l}1.11- \\
2.76\end{array}$ \\
\hline $\begin{array}{l}\text { PTS during } \\
\text { last } 12 \\
\text { months }\end{array}$ & 306 & (30.5) & & & & & & & & & & \\
\hline $\begin{array}{c}\text { Native } \\
\text { Swedish } \\
\text { speakers }\end{array}$ & 218 & (27.7) & 1 & & 1 & & 1 & & 1 & & 1 & \\
\hline $\begin{array}{l}\text { Non- } \\
\text { native } \\
\text { Swedish } \\
\text { speakers }\end{array}$ & 88 & (40.9) & 1.84 & $\begin{array}{l}1.34- \\
2.52\end{array}$ & 1.57 & $\begin{array}{l}1.12- \\
2.20\end{array}$ & 1.50 & $\begin{array}{l}1.07- \\
2.09\end{array}$ & 1.97 & $\begin{array}{l}1.42- \\
2.74\end{array}$ & 1.56 & $\begin{array}{l}1.10- \\
2.34\end{array}$ \\
\hline
\end{tabular}

a Edinburg Depression Scale, EDS $5 \geq 7$

b Posttra umatic stress, PTS at least 1 of 3 symptoms

c Model 1 Background: age of participants (continuous in years), $\leq 13$ years of education, and expeniencing financial distress.

d Model 2 Social support: age, not living with a partner, and no one to confide in.

e Model 3 Professio nal support: age of participant, and consultation with psychiatrist or

psychologist prior to pregnancy

f Model 4 Included all factors.

$\mathrm{Cl}$, confidence interval; OR, odds ratio; a OR, adjusted odds ratio 